\title{
Fournier's Gangrene: Analysis of 14 Cases
}

\author{
Mohammed Asseban*, Adil Kallat, Adil Mazdar, Hachem El Sayegh, Ali Iken, \\ Lounis Benslimane, Yassine Nouini \\ Urology A Department, Ibn Sina University Hospital, Rabat, Morocco \\ Email: assebanmh@hotmail.com
}

Received 12 June 2014; revised 16 July 2014; accepted 11 August 2014

Copyright (C) 2014 by authors and Scientific Research Publishing Inc.

This work is licensed under the Creative Commons Attribution International License (CC BY). http://creativecommons.org/licenses/by/4.0/

(c) (i) Open Access

\begin{abstract}
Introduction: Perineo-scrotal gangrene is a necrotizing fasciitis concerning soft parts of the genital area which necessitates a rapid, complete and multidisciplinary medical management. The aim of our study was to describe the epidemiologic, diagnostic and therapeutic aspects of Fournier's gangrene. Patients and methods: We have carried out a retrospective study with 14 patients with Fournier's gangrene, who were treated from January 2011 to November 2013 at the Urology A Department of Ibn Sina University Hospital, Rabat, Morocco. Results: The average age was 58 years (47 to 76 years). All patients were male. Average time (delay) between onset of infection and consultation was one week. Clinical symptomatology was dominated by edema and erythema signs, fever and pain. In most cases, skin necrosis initially affected perineo-scrotal region. $43 \%$ of patients were diabetic. 5 patients $(35 \%)$ had a urethral stricture. The most common germs found were: Escherichia coli (50\%), Streptococcus (22\%) and Klebsiella (14\%). The treatment consisted in a large debridement, associated with fluid and electrolyte replacement and parenteral broadspectrum antibiotics with drainage of urine. Orchiectomy was required in 2 patients. The average length of hospital stay was 3 weeks. 4 patients $(28 \%)$ had a scrotal collection. 2 patients (14\%) died from a toxic septic shock. Conclusion: Fournier's gangrene remains, despite the multidisciplinary medical management, a serious affection associated with high mortality. Early consultation and correction of general disorders and immune deficiencies can improve its prognosis.
\end{abstract}

\section{Keywords}

Necrotizing Fasciitis, Perineo-Scrotal Gangrene, Diabetes, Necrosectomy, Septic Shock

\section{Introduction}

Fournier's gangrene is a type of necrotizing infection or gangrene usually affecting the perineum. It is rare but

${ }^{*}$ Corresponding author. 
imposes a fast, complete and multidisciplinary medical management, because of its severity. Its mode of revelation is sometimes atypical. It is due to a polymicrobial infection by aerobic and anaerobic bacteria having a synergistic action. We describe our experience in the management of this disease by relating its epidemiological and diagnostic aspects and therapeutic modalities.

\section{Materials and Methods}

This is a retrospective study of 14 cases of Fournier gangrene collected in the Urology A Department of Ibn Sina University Hospital, from 2011 to 2014. All patients were admitted through the emergency. Diagnosis was easy. Just urologic etiologies were included. Treatment consisted of: medical reanimation, correction of hemodynamic, fluid and electrolyte disorders, antibiotherapy after bacteriological samples, combining beta-lactamine, metronidazole and aminoglycosides, surgical treatment consisting in excision of necrotic tissue and skin reconstruction in a second stage.

\section{Results}

The average age of our patients was 58 years (ranging from 47 to 76 years). All patients were men. The average delay for consultation was one week (ranging from 4 to 21 days). Symptomatology was dominated by edema and systemic signs, fever and pain. Four patients (28\%) had a scrotal collection. Skin necrosis was found in most cases, initially in the scrotum and perineum (Figure 1). The characteristic foul odor accompanied all the clinical presentations. A fever higher than $39^{\circ} \mathrm{C}$ was observed in 10 patients (71\%). Six patients (43\%) were diabetic. Five patients (35\%) had urethral stricture as etiology (Table 1). Leukocytosis greater than 10000/mm3 was noted in all patients. The most found germs on bacteriological samples were Escherichia coli in 7 patients (50\%), streptococcus in 3 patients (22\%), Klebsiella in 2 patients (14\%) and no pathogenic germs in 2 patients (14\%) (Table 2).

The treatment consisted of a large debridement during the day of admission for all patients, associated with fluid and electrolyte replacement and broad-spectrum parenteral antibiotics with drainage of urine (Figure 2). Urine drainage was done in all patients during the acute phase, by cystostomy in 4 patients (29\%) or bladder catheterization in 7 patients (50\%). Colostomy was performed in 1 patient (7\%). Orchidectomy was performed in 2 patients (14\%) for purulent melting (Table 3). Eleven patients (78\%) underwent hyperbaric oxygen therapy with satisfactory results in 9 patients (82\%).

Mean duration of hospital stay was 3 weeks (range: 7 to 52 days). Two diabetic patients (14\%) died following a toxic septic shock. Secondary sutures were performed after the acute phase and skin grafting was performed in 4 patients (28\%) (Figure 3).

\section{Discussion}

Fournier's gangrene was first described by Baurienne in 1764, but it is Jean-Alfred Fournier, who gave his name to the disease by describing, in 1883, five cases of scrotum gangrene occurring in young men, without apparent cause [1]. The incidence is not known [2].

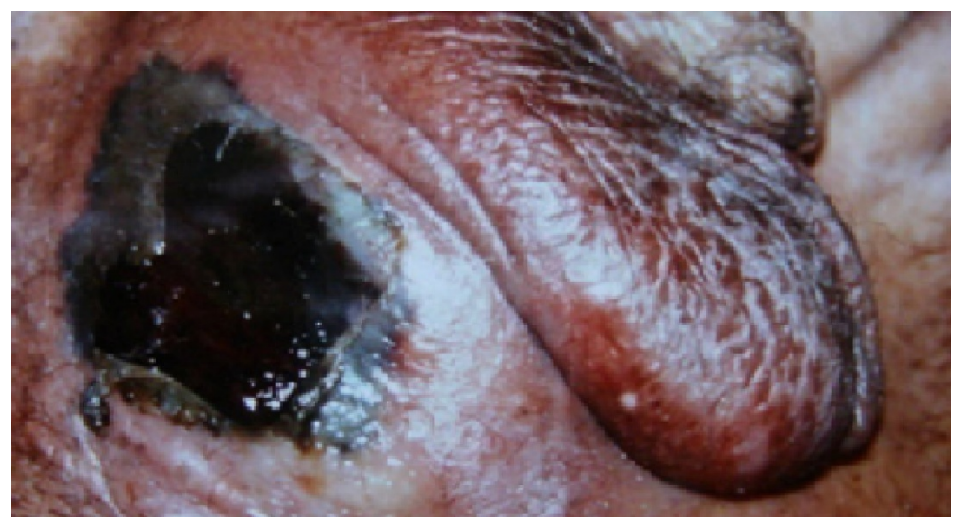

Figure 1. Fournier’s gangrene with blackish plate in the right hemi scrotum. 
Table 1. Patient's characteristics.

\begin{tabular}{ccccccc}
\hline $\begin{array}{c}\text { Average age } \\
\text { (years) }\end{array}$ & $\begin{array}{c}\text { Average delay for consultation } \\
\text { (days) }\end{array}$ & Fever $>39^{\circ}$ & Diabetes & Urethral stricture & Death & Large debridement \\
\hline 58 & 7 & $10(71 \%)$ & $6(43 \%)$ & $5(35 \%)$ & $2(14 \%)$ & $14(100 \%)$ \\
\hline
\end{tabular}

Table 2. Results of bacteriological sampling.

\begin{tabular}{ccccc} 
& Escherichia coli & Streptocoque & Klebsiella & No germs \\
\hline Number of patients & 7 & 3 & 2 & 2 \\
Percentage (\%) & 50 & 22 & 14 \\
\hline
\end{tabular}

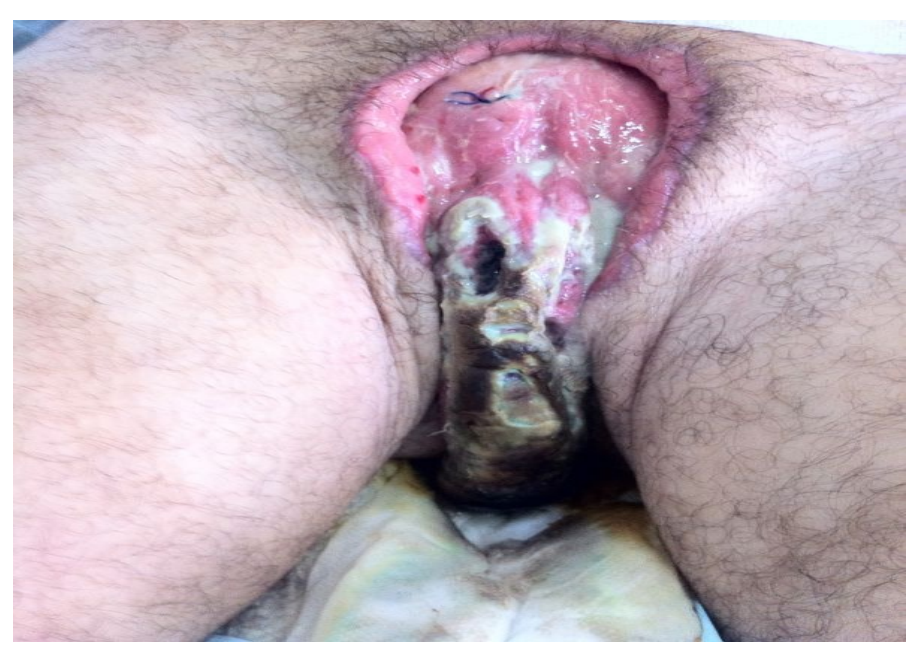

Figure 2. Fournier's gangrene: large debridement.

Table 3. Urinary drainage, colic derivation and orchidectomy.

\begin{tabular}{cccccc}
\hline & Cystostomy & Bladder catheterization & Colostomy & Unilateral orchidectomy & $\begin{array}{c}\text { Bilateral } \\
\text { orchidectomy }\end{array}$ \\
\hline Number of patients & 4 & 7 & 1 & 1 & 7 \\
Percentage (\%) & 29 & 50 & 7 & 7 \\
\hline
\end{tabular}

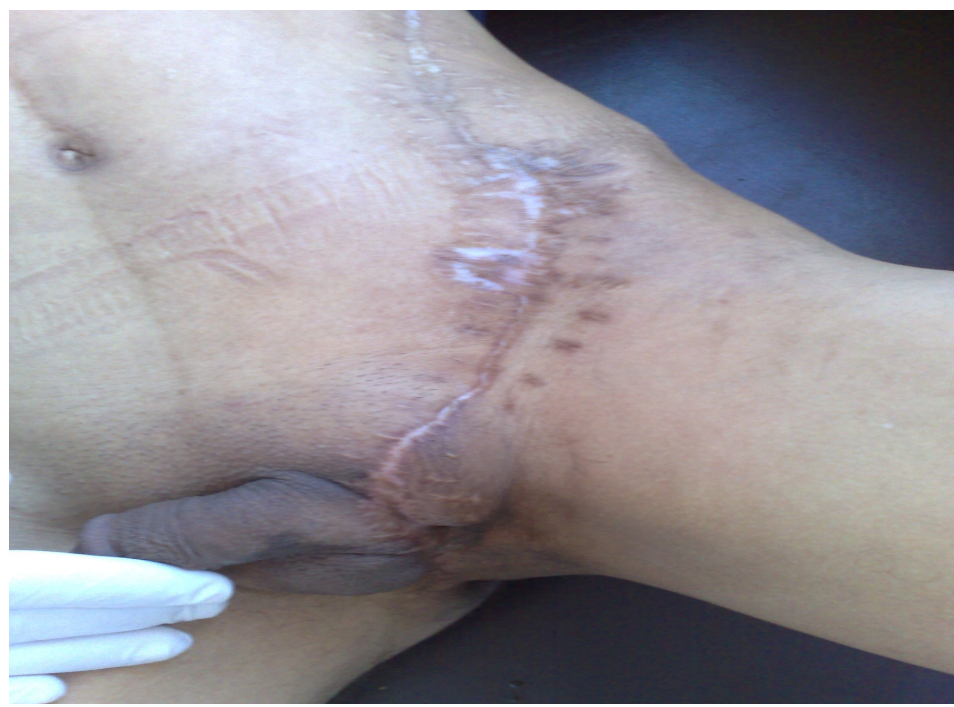

Figure 3. Fournier's gangrene: healing and budding of the excision area. 
Patient age varies between 30 and 60 years in the majority of studies. In our study, the patients' ages ranged from 47 to 76 years with an average age of 58 years. Men are ten times more affected than women [3]. Its etiology is identified in $75 \%$ to $100 \%$ of cases. It is colorectal in $13 \%-50 \%$ of cases (perirectal and perianal abscess, rectal instrumentations, colonic perforation secondary to cancer, diverticulosis, hemorrhoids cures and sexual intercourse among homosexual) and urogenital in $17 \%$ - $87 \%$ of cases (stenoses of the urethra with extravasation of urine and periurethral infection, urethral instrumentation including indwelling catheters especially in paraplegics, circumcision, hernia cure and after implantation of penile prosthesis) [4]. Other causes include skin infections and local trauma. In our study, just urologic etiologies were included and 35\% of patients had a urethral stricture as etiology.

Several factors can contribute to the development of the disease, including conditions that depress immunity: diabetes (present in $60 \%$ of cases), alcoholism, extreme ages, poor hygiene, infections acquired by immune deficiency virus (HIV), malnutrition, neoplasia, steroids, morbid obesity, pelvic vascular pathologies, cirrhosis and spinal neurological involvement with decreased sensitivity of perineum and scrotum [3]. In our study, diabetes was found in $43 \%$ of patients. It's the most common risk factor in the literature.

Radiography may show air in the subcutaneous tissue before the onset of crepitus on clinical examination [5]. Ultrasound examination showed the presence of air or subcutaneous abscess [6]. Computed tomography (CT) is the examination of choice because it is more specific (extension and etiology) [7]. In our study, additional radiological examinations were not required because they delayed the therapeutic management.

Bacteriological samples must be made systematically on pre and per-operative period with direct examination and microbiological cultures (aerobic and anaerobic). They are positive in $23 \%$ - 36\% of cases [7]. The organisms most frequently involved are: Enterobacteriaceae (Eschrichia Coli, Proteus), anaerobic (Bacteroides), Pseudomonas, Staphylococcus, Streptococcus and Enterococcus. Anaerobic Gram negative predominate in rectal etiologies and aerobic Gram positive predominate in urethral etiologies [8]. Germs found in our study were Escherichia Coli in 7 patients (50\%), Streptococcus in 3 patients (22\%) and Klebsiella in 2 patients (14\%). Empiric antibiotic therapy should be initiated quickly and associated to surgery. It should include an antibiotic active against anaerobes. Several associations can be used [9]. In our study, we used in all patients the following combination of antibiotics: beta-lactamine, aminoglycoside and metronidazole.

Surgery is paramount and must be aggressive and early. It includes debridement until macroscopically healthy tissue, washing, drainage, necrosectomy and total excision of the lesions. Suprapubic urinary drainage is recommended in extensive gangrene. In our study, 4 patients (29\%) had a cystostomy and 7 patients (50\%) had a bladder catheterization. All our patients had extensive debridement. Colostomy is to discuss systematically [10]. It was conducted only in one patient (7\%). Hyperbaric oxygen therapy allows increasing the local concentration of oxygen thus improving healing and preventing bacterial multiplication [4]. However, its effectiveness remains controversial [11]. In our study, 11 patients (78\%) underwent hyperbaric oxygen therapy with satisfactory results in 9 patients (82\%).

Persistent sepsis is the main complication of Fournier gangrene due to ignorance of its etiology, underestimation of necrosis extensive and occurrence of bacterial endocarditis, secondary pneumonia and atelectasis [12]. The highest mortalities encountered in diabetics, alcoholics and patients with colorectal infections [4]. In our study, diabetic patients (14\%) died following a toxic septic shock.

\section{Conclusion}

Fournier's gangrene is a surgical emergency. The diagnosis is often delayed. Imaging should never delay surgery. The mortality rate remains high despite advances in treatment. Medical management should be multidisciplinary after stabilization of hemodynamics.

\section{References}

[1] Fournier, J.A. (1883) Gangrène foudroyante de la verge. Medicine Pratique, 4, 589-597.

[2] Schaeffer, E.M. and Schaeffer, A.J. (2007) Infections of the Urinary Tract. In: Wein, A., Ed., Campbell-Walsh Urology, Saunders Elsevier, Philadelphia, 301-303.

[3] Eke, N. (2000) Fournier’s Gangrene: A Review of 1726 Cases. British Journal of Surgery, 87, 717-728. http://dx.doi.org/10.1046/j.1365-2168.2000.01497.x

[4] Norton, K.S., Johnson, L.W., Perry, T., Perry, K.H., Sehon, J.K. and Zibari, G.B. (2002) Management of Fournier’s 
Gangrene: An Eleven-Year Retrospective Analysis of Early Recognition, Diagnosis, and Treatment. The American Surgeon, 68, 709-713.

[5] Biyani, C.S., Mayor, P.E. and Powell, C.S. (1995) Case Report: Fournier's Gangrene-Roentnographic and Sonographic Findings. Clinical Radiology, 50, 728-729. http://dx.doi.org/10.1016/S0009-9260(05)83323-9

[6] Morrison, D., Blaivas, M. and Lyon, M. (2005) Emergency Diagnosis of Fournier's Gangrene with Bedside Ultrasound. The American Journal of Emergency Medicine, 23, 544-547. http://dx.doi.org/10.1016/j.ajem.2004.12.010

[7] Guibal, F., Muffat-Joly, M., Terris, B., et al. (1994) Necrotizing Fasciitis. Lancet, 344, 1771.

[8] Tuncel, A., Aydin, O., Tekdogan, U., et al. (2006) Fournier's Gangrene: Three Years of Experience with 20 Patients and Validity of the Fournier's Gangrene Severity Index Score. European Urology, 50, 838-43. http://dx.doi.org/10.1016/j.eururo.2006.01.030

[9] Bédos, J.P. (2006) Necrotising Cutaneous Infections and Necrotizing Fasciitis: What Antibiotic Agents to Use and How? Annales Françaises d'Anesthésie et de Réanimatio, 25, 982-985.

[10] Bronder C.S., Cowey, A. and Hill, J. (2004) Delayed Stoma Formation in Fournier's Gangrene. Colorectal Disease, 6, 518-520. http://dx.doi.org/10.1111/j.1463-1318.2004.00663.x

[11] Mindrup, S.R., Kealey, G.P. and Fallon, B. (2005) Hyperbaric Oxygen for the Treatment of Fournier's Gangrene. The Journal of Urology, 173, 1975-1977.

[12] Sarkis, P., Farran, F., Khoury, R., Kamel, G., Nemr, E., Biajini, J. and Merheje, S. (2009) Fournier’s Gangrene: A Review of the Recent Literature. Progrès en Urologie, 19, 75-84. 
Scientific Research Publishing (SCIRP) is one of the largest Open Access journal publishers. It is currently publishing more than 200 open access, online, peer-reviewed journals covering a wide range of academic disciplines. SCIRP serves the worldwide academic communities and contributes to the progress and application of science with its publication.

Other selected journals from SCIRP are listed as below. Submit your manuscript to us via either submit@scirp.org or Online Submission Portal.
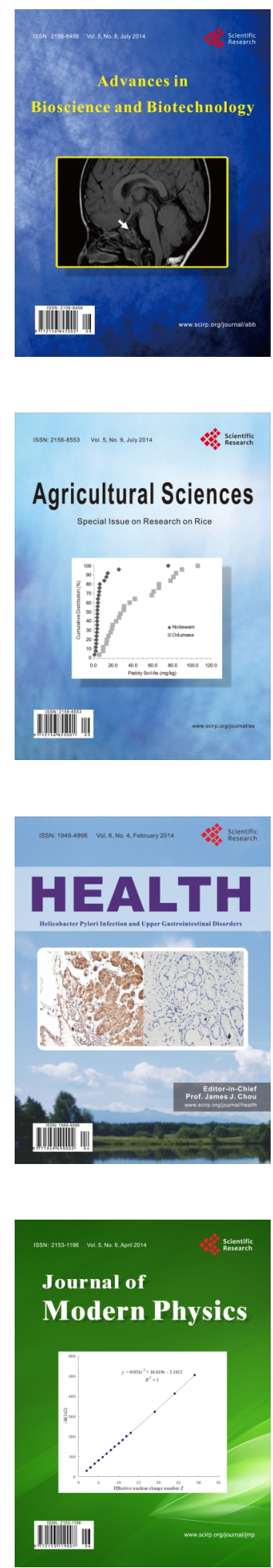
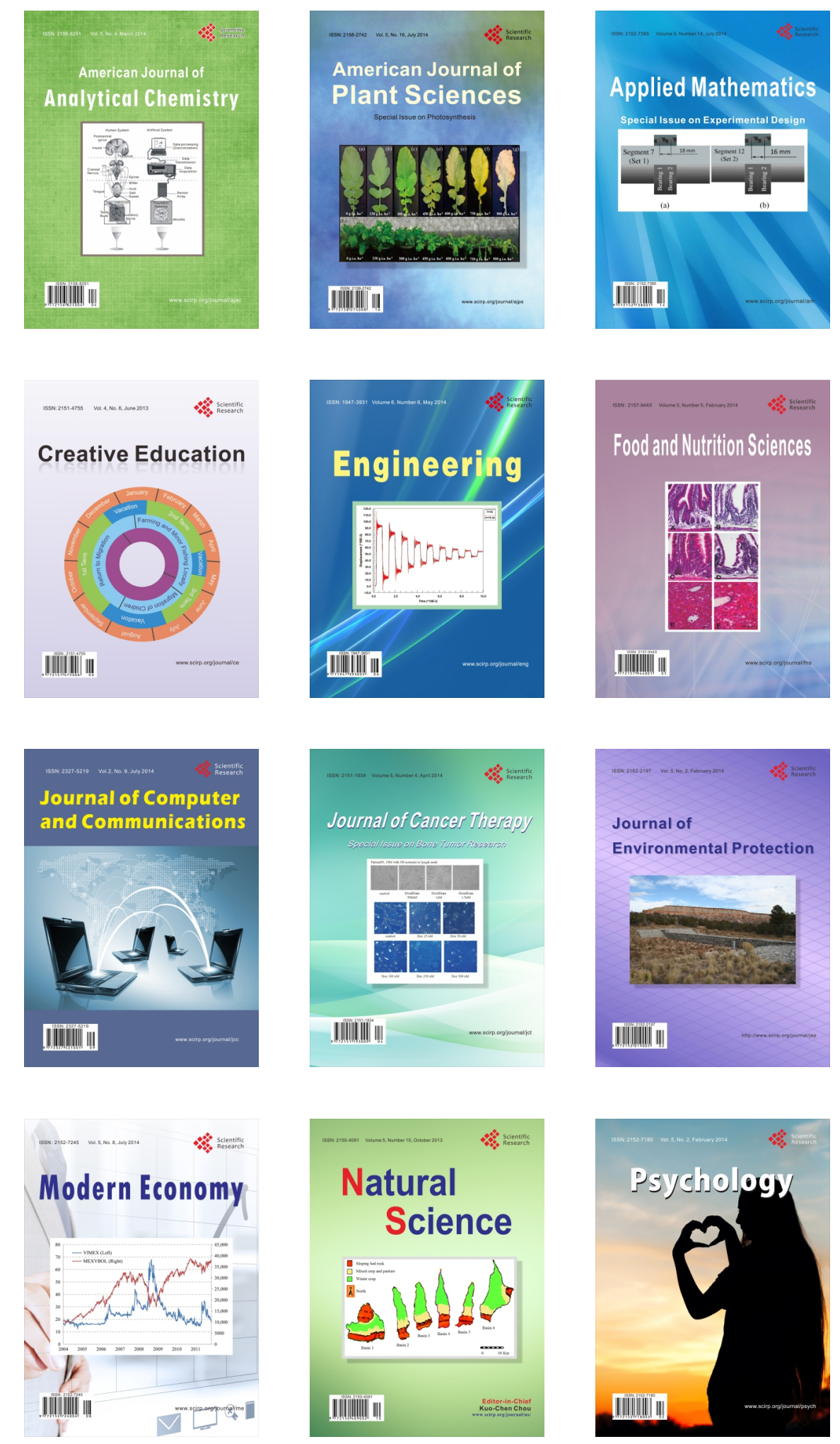